\title{
Family-based analysis of vitamin $D$ receptor gene polymorphisms and type 1 diabetes in the population of South Croatia
}

\author{
Vesna Boraska $\cdot$ Veselin Škrabić $\cdot$ Eleftheria Zeggini • \\ Christopher James Groves • Maja Buljubašić • \\ Marijana Peruzović · Tatijana Zemunik
}

Received: 12 November 2007 / Accepted: 3 December 2007/Published online: 27 December 2007

(C) The Japan Society of Human Genetics and Springer 2007

\begin{abstract}
Type 1 diabetes mellitus (T1DM) is a disease characterised by the autoimmune destruction of insulinproducing pancreatic $\beta$ cells. Vitamin $D$ is a known immune system modulator and its effects are exerted via the vitamin D receptor (VDR). Several VDR gene single nucleotide polymorphisms (SNPs) have been commonly studied in relation to T1DM. The aim of this study was to evaluate the role of $V D R$ gene variation in T1DM susceptibility by genotyping four SNPs (FokI-rs10735810, TaqI-rs731236, BsmI-rs1544410, and Tru9I-rs757343) in 160 case-parent trio samples from the population of South Croatia. We observed overtransmission of Tru9I allele G and undertransmission of the Tru9I-BsmI A-A haplotype from parents to affected children $(P=0.032, P=0.002$, respectively). These results indicate a possible role of the $V D R$ gene in T1DM aetiology. In conclusion, this familybased study presents some evidence of association of
\end{abstract}

V. Boraska $(\bowtie) \cdot$ M. Peruzović · T. Zemunik

Department of Medical Biology, Medical School,

University of Split, 21000 Split, Croatia

e-mail: vboraska@bsb.mefst.hr

\section{V. Škrabić}

Department of Pediatrics, Clinical Hospital Split,

21000 Split, Croatia

\section{E. Zeggini}

Wellcome Trust Centre for Human Genetics,

University of Oxford, Oxford, UK

\section{J. Groves}

Oxford Centre for Diabetes, Endocrinology and Metabolism, University of Oxford, Oxford, UK

M. Buljubašić

Division of Molecular Biology, Ruđer Bošković Institute,

University of Zagreb, 10000 Zagreb, Croatia specific $V D R$ gene variants with T1DM in the population of South Croatia.

Keywords Type 1 diabetes - Vitamin D receptor . TDT · Polymorphism · Genetic epidemiology · Croatia

\section{Introduction}

Type 1 diabetes mellitus (T1DM) has a strong genetic component. The most important genetic factors for determining the risk of developing T1DM reside in the human leucocyte antigen (HLA) class II loci, but several other gene regions have also been identified: a region $5^{\prime}$ to the INS gene, CTLA4 gene, PTPN22 gene, IL2RA gene and IFIH1 region (Rich et al. 2006; Smyth et al. 2006). The most recent genome-wide association study of T1DM identified another four regions: 12q24, 12q13, 16p13 and 18p11 (Todd et al. 2007).

So far, a large number of studies have suggested that the vitamin $\mathrm{D}$ receptor gene $(V D R)$ is involved in the pathogenesis of T1DM. Among different roles in the organism, vitamin $\mathrm{D}$ acts as a modulator of the immune system by promoting monocyte differentiation and inhibiting lymphocyte proliferation and secretion of several cytokines (Haussler et al. 1998; Uitterlinden et al. 2004). Maternal intake of vitamin D through food during pregnancy may protect offspring against the appearance of islet autoimmunity (Fronczak et al. 2003). Oral administration of the hormonally active form of vitamin $\mathrm{D}$ completely protects nonobese diabetic mice (NOD) mice from T1DM (Zella et al. 2003). In addition, treatment of adult NOD mice with a vitamin $\mathrm{D}$ analogue markedly reduced T1DM development (Giarratana et al. 2004). The effects of vitamin D are mediated by the VDR protein, a nuclear receptor that acts 
as a ligand-activated transcription factor. Therefore, sequence variation in the $V D R$ gene may be related to T1DM (Valdivielso and Fernandez 2006).

The VDR gene, located at chromosome 12q12-q14, has several frequently studied single nucleotide polymorphisms (SNP). These are FokI (rs10735810) G/A change in exon 2, TaqI (rs731236) T/C change in exon 9, BsmI (rs1544410) G/A and Tru9I (rs757343) G/A changes both in intron 8 (Guo et al. 2006). FokI occurs at the first start codon in exon 2 and changes the translation initiation site, resulting with three amino acids shorter truncated protein, considered to be more active than the wild type (Uitterlinden et al. 2004). It is not yet known if intronic BsmI andTru9I SNPs and a synonymous exonic TaqI SNP have any functional effect (Valdivielso and Fernandez 2006). Nevertheless, these three SNPs can be useful in association studies as markers to some other truly functional allele elsewhere within this gene region (Uitterlinden et al. 2004).

$V D R$ gene polymorphisms were largely studied in the last decade within different world populations. The results reported in those studies showed inconsistency, and Guo et al. evaluated those reports in a meta-analysis of the four VDR gene SNPs (FokI, BsmI, ApaI and TaqI) but not Tru9I (Guo et al. 2006). The authors found no evidence for an association between $V D R$ gene polymorphisms and T1DM risk. Nejentsev et al. studied 98 SNPs within the VDR gene (including four SNPs) in a larger group of 3,763 families and found no evidence of association with T1DM (Nejentsev et al. 2004). Recently, Ramos-Lopez et al. reported a protective role of several VDR haplotypes in T1DM (Ramos-Lopez et al. 2006). Also, Mimbacas et al. found FokI SNP to be associated with T1DM in a Uruguayan population (Mimbacas et al. 2007).

This family-based study is an extension of our population-based case-control studies of the $V D R$ gene variants (Skrabic et al. 2003; Zemunik et al. 2005). Previously, we found combined genotypes BBAAtt (Skrabic et al. 2003), FokI SNP and several haplotypes (Zemunik et al. 2005) to be associated with susceptibility to T1DM. The aim of this study was to analyse the transmission of FokI, TaqI, BsmI and Tru9I SNPs in case-parent trio samples and to evaluate their association with susceptibility to T1DM in the population of South Croatia.

\section{Materials and methods}

\section{Subjects}

We typed 132 parent-offspring trios, 20 parent-offspring duos, seven families with two affected children and one family with three affected children from the population of South Croatia. Each proband was ascertained with T1DM according to the World Health Organisation criteria. Gender distribution among affected children was $83(49.11 \%)$ males and $86(50.08 \%)$ females, and the mean age at the onset of T1DM was $8.86 \pm 5.36$ [mean \pm standard deviation (SD)]. This study was approved by the ethics committee, and informed consent from was obtained from patients and their parents prior to blood sampling.

\section{Genotyping}

Genomic DNA was extracted from peripheral blood leukocytes using the QIAamp DNA Blood Mini Kit (Qiagen, Hilden, Germany). Genotypes for four VDR SNPs (FokIrs10735810, TaqI-rs731236, BsmI-rs1544410 and Tru9Irs757343) were identified by polymerase chain reaction (PCR) followed by restriction fragment-length polymorphism (RFLP) (Ban et al. 2001; Chang et al. 2000; Ye et al. 2000). The digested fragments were separated in $8 \%$ polyacrylamide gels (FokI and Tru9I) and 3\% agarose gels (TaqI and BsmI) and visualised by ethidium bromide staining. Genotypes were determined according to the presence or absence of restriction site, and alleles were designated respective to actual base change according to the dbSNP (http://www.ncbi.nlm.nih.gov/projects/SNP/).

As a measure of quality control (QC), all samples were checked for gender status using a fluorescence-based competitive allele-specific assay (Kaspar, Kbioscience, UK). The assay investigates the single base difference between a homologous exon of the $Z F X$ and $Z F Y$ genes and is diagnostic for sex chromosome (assay details are available from the authors on request).

\section{Statistical analysis}

Prior to association analysis, we performed QC of the obtained genotypes. As a part of QC, data was tested for Mendelian inheritance and missing genotypes using Plink (Purcell et al. 2007). Hardy-Weinberg equilibrium (HWE) in healthy parents was tested using Pedstats (Wigginton and Abecasis 2005). Minor allele frequencies (MAF) were compared with phase II HapMap (http://www.hapmap.org) MAF from the CEU population (The International HapMap Consortium 2003). Single-point and multipoint association analyses were carried out using Plink and Unphased (Dudbridge 2003) implementations of the transmission disequilibrium test (TDT). Power calculation for every investigated SNP was performed using Quanto (Gauderman 2003). To obtain empirical $P$ values, 10,000 permutations were run for each analysis, and permutation $P$ values less than 0.05 were considered nominally significant. 


\section{Results}

Gender-control genotyping identified six discrepancies when compared with database information. These six individuals and their families were excluded from further analysis. No Mendel errors were found in the rest of the obtained genotyped trios. FokI and Tru9I SNPs were genotyped for every sample, and the percentage of missing genotypes per TaqI and BsmI SNPs were $1.3 \%$ and $0.8 \%$, respectively. BsmI SNP was out of HWE, and TaqI was at the limit of the significance in healthy parents $(P=0.0026$ and $P=0.0282$, respectively). MAF in healthy parents were concordant with phase II HapMap frequencies from the CEU (European descent) population. After QC analysis, 154 cleaned-up families were submitted to further analyses.

TDT single-point analysis detected nominally significant overtransmission of the Tru9I common allele $\mathrm{G}$ from parents to affected child $[P=0.032$, odds ratio $(\mathrm{OR})=$ $1.73,95 \%$ confidence interval (CI) 1.041-2.904, permutation 10,000]. Results of TDT analysis are shown in Table 1. Exhaustive TDT multipoint search for haplotypic effects observed an association with Tru9I-BsmI haplotypes $(P=0.005$, permutation 10,000$)$. Specifically, the Tru9I-BsmI A-A haplotype was undertransmitted from parents to affected offspring $(P=0.002)$ (Table 2). This study had $80 \%$ statistical power to detect (at $\alpha=0.05$ ) an effect of OR = 1.6 for FokI, TaqI and BsmI and 65\% power for $\mathrm{OR}=1.73$ for Tru9I, assuming an additive model.

\section{Discussion}

In this study, we found some evidence of association of VDR gene Tru9I polymorphism and Tru9I-BsmI haplotype with T1DM in the population of South Croatia. However, this study has several limitations. First, our sample size was not big enough to detect an effect of OR $=1.73$ for Tru9I SNP (we had $65 \%$ statistical power). Second, we performed a number of tests and did not correct for multiple testing. However, for every significant result, we ran
10,000 permutations and reported a permutation $P$ value. Third, we observed a deviation of BsmI SNP from HWE. This deviation could reflect on the positive results of Tru9IBsmI haplotype we found. Nevertheless, the possibility of true finding should not be excluded.

There are several positive aspects of this study. It investigates four $V D R$ gene variants in the T1DM families from South Croatia for the first time. It contributes to the overall knowledge of the relation of the $V D R$ gene and T1DM. It is designed to be compatible for comparisons between different populations and will be useful for future meta-analysis of the VDR gene.

We observed a deviation in transmission of Tru9I alleles (overtransmission of allele G; i.e. undertransmission of minor allele A) from parents to affected offspring. The Tru9I MAF of the affected probands (0.099), due to its undertransmission, is expectedly lower than the MAF of the HapMap for CEU populations (0.133). But this difference is not significant $(P=0.340)$. We also observe a pattern of undertransmission of Tru9I-BsmI A-A haplotype. All these results support the idea of a possible protective role of the Tru9I minor allele in T1DM aetiology.

We have already analysed $V D R$ gene variants with T1DM in two population-based case-control studies (Skrabic et al. 2003; Zemunik et al. 2005). Our results presented here were unable to confirm previously reported single-point associations. In multipoint analysis, we could not detect significant associations of previously reported haplotypes (BatU, FbATu and fBATU) with T1DM (Zemunik et al. 2005). However, in this family-based study, we observe the same trend towards protectiveness;

Table 2 Transmission of Tru9I-BsmI haplotypes in 154 parent-offspring trio families

\begin{tabular}{lllll}
\hline Haplotype & $T$ & $U$ & $\chi^{2}$ & $P$ value \\
\hline A-A & 4.216 & 18.86 & 9.291 & 0.002 \\
G-A & 73.78 & 56.14 & 2.396 & 0.122 \\
A-G & 18.78 & 21.14 & 0.1393 & 0.709 \\
G-G & 62.22 & 62.86 & 0.003295 & 0.954 \\
\hline
\end{tabular}

Numbers of transmitted $(T)$ and nontransmitted $(U)$ haplotypes

Table 1 Transmission disequilibrium analysis of minor allele of four vitamin D receptor gene single nucleotide polymorphisms (VDR SNPs) in 154 parent-offspring trio families

\begin{tabular}{|c|c|c|c|c|c|c|c|c|c|}
\hline SNP & CA & MA & MAF & $T: U$ & OR & $L 95$ & $U 95$ & $\chi^{2}$ & $P$ value \\
\hline TaqI (rs731236) & $\mathrm{T}$ & $\mathrm{C}$ & 0.447 & $65: 54$ & 1.204 & 0.84 & 1.73 & 1.017 & 0.313 \\
\hline Tru9I (rs757343) & G & A & 0.099 & $23: 40$ & 0.58 & 0.34 & 0.96 & 4.587 & 0.032 \\
\hline BsmI (rs1544410) & $\mathrm{G}$ & A & 0.494 & $57: 54$ & 1.06 & 0.73 & 1.53 & 0.081 & 0.776 \\
\hline FokI (rs10735810) & G & A & 0.407 & $74: 73$ & 1.01 & 0.73 & 1.40 & 0.007 & 0.934 \\
\hline
\end{tabular}

$C A$ common allele, $M A$ minor allele, $M A F$ minor allele frequencies in type 1 diabetes mellitus (T1DM) children, $T: U$ copies of the minor allele transmitted $(T)$ and nontransmitted $(U)$ from heterozygous parents to affected offspring 
i.e. we observed relative undertransmission of similar haplotypes from parents to affected children (BtU, FbTu and fBTU; i.e. GCG, GATA and AGTG, respectively) but without reaching significant difference.

Yet published findings on association of several SNPs in the VDR gene with a risk of developing T1DM have been conflicting. Guo et al. tried to evaluate these findings in a meta-analysis of FokI, TaqI, BsmI and ApaI polymorphisms and found no evidence of association (Guo et al. 2006). However, they did not analyse the Tru9I variant. Nejentsev et al. developed a VDR gene SNP map and tested all common variation of this gene, including four variants from our study, in five different populations. Their results indicated no major effect of common variation in the VDR gene and susceptibility to T1DM (Nejentsev et al. 2004). Recently, Ramos-Lopez et al. investigated 11 polymorphisms, also including the same four polymorphisms from our study, in German families. They found several VDR gene haplotypes to be negatively associated with T1DM (Ramos-Lopez et al. 2006). Mimbacas et al. investigated three VDR SNPs and found FokI to be an indicator for susceptibility to T1DM in a Uruguayan population (Mimbacas et al. 2007). Recent reports remain equivocal, and a replication of the study in a bigger sample is needed.

The incidence of T1DM has large geographical variations, which might be caused by differences in frequencies of genetic markers among different populations (Angel et al. 2004). Findings from our study might indicate the differences in the genetic background between studied populations and/or could point out linkage to truly causal variants somewhere else within this chromosomal region (Valdivielso and Fernandez 2006).

Our study investigated four VDR gene SNPs in several T1DM families of South Croatia. We found evidence of association of Tru9I SNP and Tru9I-BsmI haplotype with T1DM. Further work should focus on the synthesis of published results and analyses in a larger sample to clarify the role of the $V D R$ gene as T1DM marker.

Acknowledgments We thank Prof. Mark McCarthy for giving an opportunity to one of our members to visit his group in the Wellcome Trust Centre for Human Genetics, University of Oxford, to learn and work in the area of statistical genetics and for all the help he provided. We also thank all members of his group. We thank The British Scholarship Trust for the support for the study visit in Oxford. This study was supported by the Croatian Ministry of Science, Education and Sports (Project number 216-1080315-0293).

\section{References}

Angel B, Santos JL, Carrasco E, Albala C, Perez-Bravo F (2004) Vitamin D receptor polymorphism and susceptibility to type 1 diabetes in Chilean subjects: a case-parent study. Eur J Epidemiol 19:1085-1087
Ban Y, Taniyama M, Yanagawa T, Yamada S, Maruyama T, Kasuga A, Ban Y (2001) Vitamin D receptor initiation codon polymorphism influences genetic susceptibility to type 1 diabetes mellitus in the Japanese population. BMC Med Genet 2:7. doi: 10.1186/1471-2350-2-7

Chang TJ, Lei HH, Yeh JI, Chiu KC, Lee KC, Chen MC, Tai TY, Chuang LM (2000) Vitamin D receptor gene polymorphisms influence susceptibility to type 1 diabetes mellitus in the Taiwanese population. Clin Endocrinol 52(5):575-580

Dudbridge F (2003) Pedigree disequilibrium tests for multilocus haplotypes. Genet Epidemiol 25:115-121

Fronczak CM, Barón AE, Chase HP, Ross C, Brady HL, Hoffman M, Eisenbarth GS, Rewers M, Norris JM (2003) In utero dietary exposures and risk of islet autoimmunity in children. Diabetes Care 26(12):3237-3242

Gauderman WJ (2003) Candidate gene association studies for a quantitative trait, using parent-offspring trios. Genet Epidemiol 25:327-338

Giarratana N, Penna G, Amuchastegui S, Mariani R, Daniel KC, Adorini L (2004) A vitamin D analog down-regulates proinflammatory chemokine production by pancreatic islets inhibiting $\mathrm{T}$ cell recruitment and type 1 diabetes development. J Immunol 173(4):2280-2287

Guo SW, Magnuson VL, Schiller JJ, Wang X, Wu Y, Ghosh S (2006) Meta-analysis of vitamin $\mathrm{D}$ receptor polymorphisms and type 1 diabetes: a HuGE review of genetic association studies. Am J Epidemiol 164(8):711-724

Haussler MR, Whitfield GK, Haussler CA., Hsieh JC, Thompson PD, Selznick SH, Dominguez CE, Jurutka PW (1998) The nuclear vitamin D receptor: biological and molecular regulatory properties revealed. J Bone Miner Res 13(3):325-349

Mimbacas A, Trujillo J, Gascue C, Javiel G, Cardoso H (2007) Prevalence of vitamin D receptor gene polymorphism in a Uruguayan population and its relation to type 1 diabetes mellitus. Genet Mol Res 6(3):534-542

Nejentsev S, Cooper JD, Godfrey L, Howson JM, Rance H, Nutland S, Walker NM, Guja C, Ionescu-Tirgoviste C, Savage DA, Undlien DE, Ronningen KS, Tuomilehto-Wolf E, Tuomilehto J, Gillespie KM, Ring SM, Strachan DP, Widmer B, Dunger D, Todd JA (2004) Analysis of the vitamin D receptor gene sequence variants in type 1 diabetes. Diabetes 53(10):27092712

Purcell S, Neale B, Todd-Brown K, Thomas L, Ferreira MAR, Bender D, Maller J, de Bakker PIW, Daly MJ, Sham PC (2007) PLINK: a toolset for whole genome association and population-based linkage analysis. Am J Hum Genet 81(3):559-575

Ramos-Lopez E, Jansen T, Ivaskevicius V, Kahles H, Klepzig C, Oldenburg J, Badenhoop K (2006) Protection from type 1 diabetes by vitamin D receptor haplotypes. Ann NYAcad Sci 1079:327-334

Rich SS, Concannon P, Erlich H, Julier C, Morahan G, Nerup J, Pociot F, Todd JA (2006) The type 1 diabetes genetics consortium. Ann NY Acad Sci 1079:1-8

Skrabic V, Zemunik T, Situm M, Terzic J (2003) Vitamin D receptor polymorphism and susceptibility to type 1 diabetes in the Dalmatian population. Diabetes Res Clin Pract 59(1):31-35

Smyth DJ, Cooper JD, Bailey R, Field S, Burren O, Smink LJ, Guja C, Ionescu-Tirgoviste C, Widmer B, Dunger DB, Savage DA, Walker NM, Clayton DG, Todd JA (2006) A genome-wide association study of nonsynonymous SNPs identifies a type 1 diabetes locus in the interferon-induced helicase (IFIH1) region. Nat Genet 238(6):617-619

The International HapMap Consortium (2003) The International HapMap project. Nature 426:789-796

Todd JA, Walker NM, Cooper JD, Smyth DJ, Downes K, Plagnol V, Bailey R, Nejentsev S, Field SF, Payne F, Lowe CE, Szeszko JS, 
Hafler JP, Zeitels L, Yang JH, Vella A, Nutland S, Stevens HE, Schuilenburg H, Coleman G, Maisuria M, Meadows W, Smink LJ, Healy B, Burren OS, Lam AA, Ovington NR, Allen J, Adlem E, Leung HT, Wallace C, Howson JM, Guja C, IonescuTirgoviste C, Genetics of Type 1 Diabetes in Finland, Simmonds MJ, Heward JM, Gough SC, Wellcome Trust Case Control Consortium, Dunger DB, Wicker LS, Clayton DG (2007) Robust associations of four new chromosome regions from genomewide analyses of type 1 diabetes. Nat Genet 39(7):857-864

Uitterlinden AG, Fang Y, van Meurs JB, van Leeuwen H, Pols HA (2004) Vitamin D receptor gene polymorphisms in relation to vitamin D related disease states. J Steroid Biochem Mol Biol 8990(1-5):187-193

Valdivielso J, Fernandez E (2006) Vitamin D receptor polymorphisms and diseases. Clin Chim Acta 371(1-2):1-12
Wigginton JE, Abecasis GR (2005) PEDSTATS: descriptive statistics, graphics and quality assessment for gene mapping data. Bioinformatics 21(16):3445-3447

Ye WZ, Reis AF, Velho G (2000) Identification of a novel Tru9 I polymorphism in the human vitamin D receptor gene. J Hum Genet 45(1):56-57

Zella JB, McCary LC, DeLuca HF (2003) Oral administration of 1,25-dihydroxyvitamin D3 completely protects NOD mice from insulin-dependent diabetes mellitus. Arch Biochem Biophys 417(1):77-80

Zemunik T, Skrabic V, Boraska V, Diklic D, Marinovic Terzic I, Capkun V, Peruzovic M, Terzic J (2005) FokI polymorphism, vitamin D receptor and interleukin-1 receptor haplotypes are associated with type 1 diabetes in the Dalmatian population. $\mathbf{J}$ Mol Diagn 7(5):600-604 